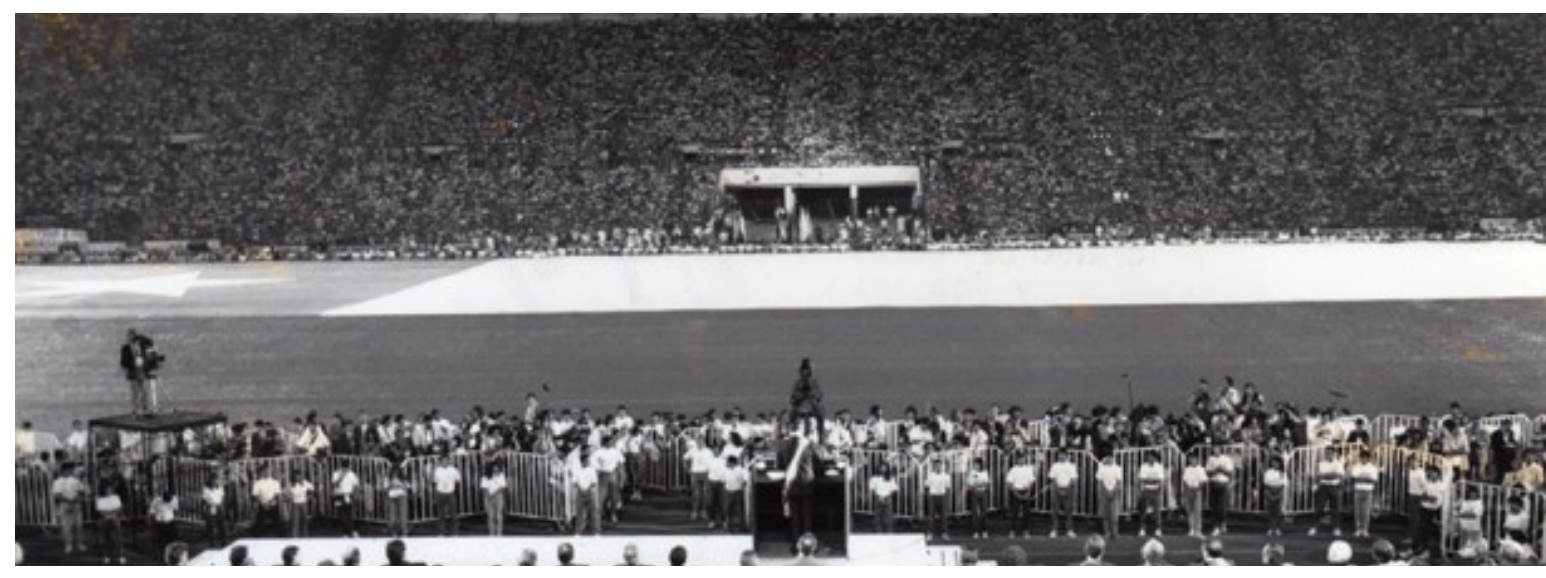

\title{
LA REPARTICIÓN DE LOS AFECTOS. ESCENAS DE CONSENSO Y DISENSO EN EL CHILE DE
}

LA TRANSICIÓN

Cynthia Shuffer ${ }^{1}$

\section{Resumen/Abstract}

El propósito del presente texto será analizar algunos acontecimientos claves del retorno a la democracia en Chile, particularmente el acto inaugural del gobierno de Patricio Aylwin llamado "Así me gusta Chile", realizado en el Estadio Nacional el año 1990. Intentaremos evidenciar el rol del estado en la repartición de los afectos -su institución y distribución- con el fin de reconstruir el entramado social nacional durante la transición a la democracia. Además, revisaremos algunos episodios posteriores, principalmente las movilizaciones estudiantiles del 2011, buscando problematizar las escenas impuestas de reconciliación y encuentro social y su proyección en los espacios actuales de participación y descontento.

Palabras claves: Transición, democracia, afectividad, representaciones políticas, imágenes.

THE PARTITION OF THE EFFECTS. SCENES OF CONSENSUS AND DISSENTS IN THE CHILE OF THE TRANSITION

The aim of this paper is to analyse some key events in Chile's return to democracy. In particular, it will look at the inaugural event of Patricio Aylwin's administration, called "Asi me Gusta Chile" [I like Chile's this way], that took place in the National Stadium in 1990. I set out to reveal the role of the state in allocating affections - their creating and distributing it - in order to reconstruct the national social tissue during the Chilean transition to democracy. Moreover, I will explore some late episodes -mainly the student demonstrations in 2011- with the purpose of problematizing the imposed images of reconciliation and citizen encounter, and their projection onto current spaces of participation and discontent.

Keywords: transition, democracy, affection, representations in Politics, images

1 Chilena, Instituto de Estudios Avanzados de la Universidad de Santiago (IDEA-USACH). E-mail: cynthia.shuffer@usach.cl 


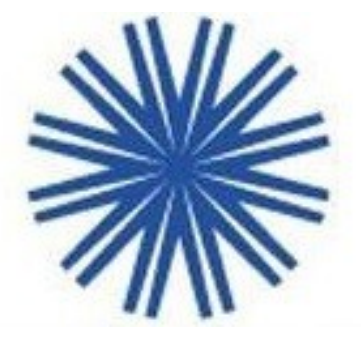

A modo de introducción

Las transformaciones políticas y sociales en los escenarios de la transición chilena provocaron una serie de modificaciones en la forma de sentir de las personas. La realidad, compuesta de complejas relaciones entre lo institucional, lo político y las formas de participación, fue convirtiéndose en un espacio en disputa entre quienes quisieron imponer una hegemonía neoliberal y aquellos que se enfrentaron a dichas formas de convivencia, en un país recientemente articulado luego de un largo periodo de abusos y silencio. El poder ejercido por la clase dominante, primero para el levantamiento y luego para la continuidad del modelo, busca, entre otras cosas, reconfigurar el entramado social con el fin de instaurar un sentimiento de pertenencia en la comunidad: esto quiere decir, una memoria colectiva unívoca y un conjunto de valores y normas compartidas por los sujetos que habitan un mismo periodo histórico-político. Sin embargo, la realidad entendida como "infinitud de fragmentos" (Lechner 1988: 13) desborda todo intento de ordenamiento, otorgando un valor particular a la pertenencia. Entenderemos aquí este concepto como la relación entre las condiciones y formas de vida de un pueblo dentro de este patrón democrático conflictivo, el cual distribuye maneras de sentir -imaginario políticoafectivo- frente a sucesos determinados.

Siguiendo esta idea, podemos decir que "todo orden social pretende ser una totalidad" (Tapia 2006: 85) y para esto requiere contener en sí mismo una estructura de sentidos que permita organizar las prácticas de la vida social. Según Tapia, dichas totalidades nunca son completas, ni mucho menos perfectas, pues implican lógicas de subordinación y marginación de otras formas de organización y comprensión del quehacer social. El acontecer histórico de una sociedad se encuentra sometido a los filtros de una institucionalidad, la que se encarga de regular el espacio de acción de sus participantes. La transición en Chile -que luego se extenderá en lo que se ha denominado postdictadura- se caracterizó por llevar adelante estrictas reglas de convivencia. La política de los consensos, las conveniencias legales para comprender los crímenes y el avance cuidadosamente milimétrico hacia un tipo de democracia (Otano, 2006:9) fueron instituyendo una política indolora, una transición sin ruptura.

Fue así como los tiempos políticos del proyecto democrático chileno establecieron escenarios específicos con el fin de ir reconstruyendo el tejido afectivo de los ciudadanos, quienes debían apresurarse por encontrar un lugar al cual pertenecer. A la luz de este análisis, resulta relevante definir 
esta idea pues guarda relación con los procesos que buscan imponer una nueva normatividad mediante lógicas propias de la democratización. Desde una perspectiva afectiva, el impacto inmediato de este proyecto recae en la propia experiencia enfrentada al quiebre del modelo opresor anterior, esto quiere decir, un tipo de "dimensión subjetiva de la política" (Lechner 1988: 13), que explora y abre experiencias nuevas, atravesada por deseos y miedos, que nos permite examinar, desde una mirada política, el estado de las cosas.

El recorrido propuesto para este análisis se traza a partir de un guion que pretende articular imágenes diversas, sin omitir la dimensión afectiva que nos proponen. Si bien, como mencionamos anteriormente, todo ordenamiento podría considerarse arbitrario o ilusorio, mediante la reconstrucción de cada contexto, asociado a estos escenarios políticos, podemos generar vínculos, expresiones simbólicas y políticas, para pensar un nuevo orden dispuesto al cambio, una transformación de las maneras de percibir el modelo administrado.

\section{0: La puesta en orden de los afectos}

El primer momento, podríamos decir inaugural, de este proceso de transición fue el Acto de Retorno a la Democracia "Así me gusta Chile", organizado por el gobierno electo y un grupo de publicistas a cargo de la campaña del "No", celebrado en el Estadio Nacional el 12 de marzo de 1990 en presencia de setenta mil personas (Otano, 2006:131). Este primer encuentro popular se convirtió en el sello simbólico de un nuevo comienzo, conectado al pasado en la medida de lo posible, animado por superar ciertos antagonismos en pos de una "patria, libre buena y justa” (Ortega y Moreno, 2002:231).

Para visualizar con mayor amplitud el "renacimiento democrático" (Otano 9) resulta necesario analizar algunos antecedentes previos a dicho acto. En la concentración realizada en el Hotel San Francisco el 14 de diciembre de 1989, el mandatario recientemente elegido, Patricio Aylwin, ofrece un primer discurso una vez oficializado su triunfo. La primera frase enunciada inaugura el proyecto de reconciliación y encuentro propuesto por el gobierno entrante: "Hoy día el pueblo de Chile ha tomado otra vez en sus manos su destino futuro" (Délano, 1989). La figura de tomar el futuro en sus manos da un giro al tono de la época, convocando a los ciudadanos a conectarse nuevamente con un presente posible, tocarlo con cierta propiedad, y dar comienzo al proceso colectivo de reconstrucción nacional. Por otro lado, la responsabilidad por definir un nosotros o pueblo de Chile recae en quienes participan del ahora, tiempo 
ineludiblemente conflictivo, pues resulta necesario establecer balances entre los efectos de la dictadura, las ausencias y experiencias de quienes sufrieron abusos y el quiebre institucional de un Estado que buscaba reencontrarse con su representatividad.
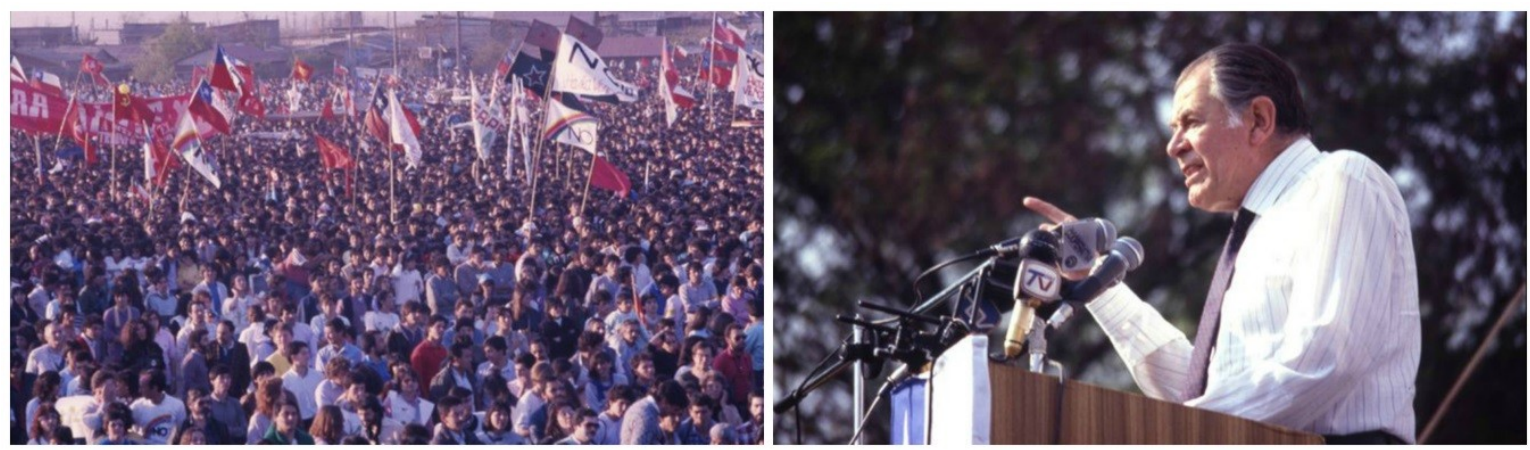

14 de Diciembre de 1989 - Archivo Memoria Chilena - Fotografías Luis Navarro

El día de las elecciones presidenciales, la multitud se agolpaba en las calles de Santiago y de todo Chile. El centro de la capital se convirtió en el escenario de una fiesta improvisada, "una noche de abrazos estrechos y eufóricos" (Délano, 1989), plagada de gritos nerviosos que demostraron el sentir de quienes aún no creían lo que estaba sucediendo. Esta épica de una ciudadanía, sobrecogida por un sentimiento de esperanza, se opuso a la angustia y el miedo que gobernó durante diecisiete años y avanzó hacia la Alameda, desafiando la prohibición del régimen militar de manifestarse y la petición de quedarse en sus casas. Las jornadas de protesta nacional durante los 80, el no emblemático de 1988 y el trazo en la papeleta presidencial de 1989 estuvieron movilizados por el deseo de abandonar la pesadilla sofocante de la dictadura, un comienzo con manos vacías, dirá Bloch, en la búsqueda de algo que no se tiene y se requiere (Bloch, 1977:15). En ese sentido, el presente se desplegaba como un tiempo inédito, donde la posibilidad de disentir se hacía palpable.

Sin embargo, el dispositivo de la memoria oficial de la transición buscó conducir y apaciguar los afectos relacionados con el recuerdo, obliterando las luchas por el sentido y las interpretaciones de un pasado en discordia (Richard, 2010:17). El mecanismo político para la integración forzada de una comunidad dañada funcionó de la siguiente manera: por un lado, el gobierno fue dictando las normas necesarias para administrar vínculos con la historia reciente, proyectando una línea directa entre esta experiencia y un tipo de ciudadano modelo, y por otro, el encuentro de las personas con esa construcción da inicio a un proceso de negociación ante la propuesta. Este procedimiento es lo que hemos llamado repartición de los afectos-siguiendo los planteamientos de Rancière-, la evidencia de una existencia común y el 
recorte ideológico que delimita los lugares para la participación. En resumen, significa instituir un acuerdo para luego distribuirlo, totalizando el sentir de las personas.

Dicha repartición estuvo acompañada por imágenes - discursos publicitarios e ideológicos- destinadas a intensificar cierta estructuración afectiva por sobre otras. El proceso de “ciudadanización” (Tapia, 2006:87) realizado en el marco de "Así me gusta Chile" abre las puertas a un tipo de reconocimiento de los derechos civiles correspondientes a las clases oprimidas durante la dictadura, ofreciendo en el acto un referente representacional parcial, equívoco y desmedido. La inclusión sin participación política ofrece un tipo de espejismo utópico, señalado por Bloch como "la esperanza fraudulenta" o "Corruptio optimi pessima", aquella corrupción de los acuerdos debido a la prevalencia de los buenos intereses. La “utopía del buen orden” (Lechner, 1988:16) en contraposición con la señalada anteriormente, delimita un espacio conflictivo, objeto de muy distintas interpretaciones. Si bien, "toda política instituye, ratifica o modifica determinadas orientaciones del quehacer social" (Lechner, 1988:17), resulta necesario destinar tiempo para pensar esquemas representativos -imaginarios y afectivos- nuevos. Esto significa hacer frente a los buenos intereses para redefinir colectivamente lo posible, lo visible y lo sensible, instaurando un marco interpretativo distinto.

La frase que da inicio al acto, "Chile ha vuelto después de años de desencuentro al camino de la libertad y de la democracia"2, contiene en sí misma una densidad retórica eufemística significativa: ¿qué oculta la palabra desencuentro y qué límites tiene la libertad y la democracia? Este enunciado y la dinámica institucional que conlleva dejan fuera de campo la experiencia social, cotidiana o personal, invisibilizando todo tipo de desacuerdo en las formas de percibir estos términos y en la reconfiguración de la libertad como espacio para el encuentro.

\section{El borde afectivo de los símbolos: La bandera del Estadio Nacional}

El retorno a la democracia originó un distanciamiento de las narrativas autoritarias de representación para reinventar una identidad nacional que permitiera recomponer el lazo social de la comunidad chilena. Sin embargo, esta distancia conlleva una particular relación con las imágenes del pasado, debido a una doble diferenciación: no se trata solamente del distanciamiento de la dictadura sino también del

2 Registro audiovisual. Yo amo los 90 Primer capítulo "Chile a las puertas del cambio". Producción de Canal 13. https://www.youtube.com/watch?v=hLqDzI0G5ag Revisada el 22 de mayo de 2015. 
$\overline{\text { trauma. Los grupos de poder -élites y dirigentes - seleccionaron un conjunto de símbolos en función de }}$ sus proyectos políticos, logrando instalar una homogeneidad afectiva mediante un disciplinamiento político. En ese sentido, el nuevo estado democrático neoliberal administra y renueva periódicamente las formas de pertenecer, "reduciendo lo social a un simple medio" (Tapia, 2006:20). Lo mismo sucede con el modelamiento de los afectos cuando se instala el consenso como la única posibilidad ante la disputa, logrando imponer ciertos acuerdos sobre la dictadura, convirtiéndose rápidamente en el "fundamento normativo para dotar de sentido a los procedimientos institucionales" (Lechner, 1988:38) de la transición. De acuerdo con esto, el reconocimiento de las luchas del pasado, el lugar de las personas en este presente conflictivo, la moderación de la justicia, etc. se encontrarían atravesados por un tipo de acuerdo sin debate, estableciendo particulares filtros de significación de acuerdo a las voluntades políticas. Esto, sin duda, restringe el acceso a otros marcos interpretativos, condicionando la experiencia único medio posible para su existencia.
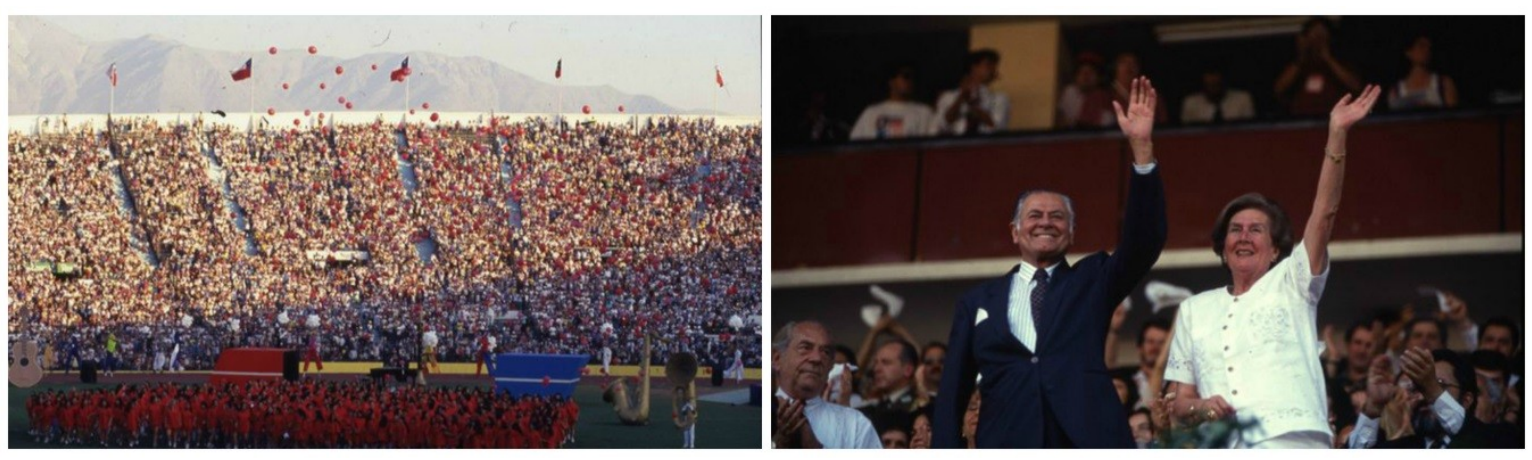

12 de marzo de 1990 - Archivo Memoria Chilena - Fotografías Luis Navarro

El acto "Así me gusta Chile" dio lugar a una concentración masiva en el Estadio Nacional con motivo de celebrar el retorno a la democracia. El programa de discursos y testimonios, tanto de familiares de detenidos desaparecidos como de figuras de la cultura proscritas durante la dictadura, estuvo acompañado por el despliegue de una enorme bandera que cubrió la cancha principal del estadio. La larga preparación del evento estuvo mediada por minuciosas negociaciones entre quienes participaron: por un lado, el gobierno pretendía enarbolar una ceremonia de los abrazos, una conveniente liturgia del perdón, y, por otro lado, "la Comisión de Derechos Humanos buscaba levantar un acto de reparación en el lugar más evidente de represión del régimen militar” (Otano, 2006:130). La fiesta inaugura lo lógica del promedio, una especie de sinopsis de los procedimientos que pondrían orden a los afectos, lugar donde se gestó la fórmula de verdad y justicia en la medida de lo posible. 
Dicha ceremonia se inaugura con la llegada del presidente, acompañado de su esposa Leonor, quienes cruzan la cancha de fútbol en dirección a la tribuna. El paso, musicalizado por el himno "Libertad" de Nabucco de Verdi, destapó, como una caja de pandora, toda la emotividad que hasta entonces fue vivida a puertas cerradas. Siguiendo sus pasos, entran a escena cientos de jóvenes vestidos con poleras blancas y toda una serie de expresiones culturales propias del territorio chileno. Una nueva subjetividad se fundaba a partir de este momento, configurando la experiencia que da cabida a renovados modos del sentir (Rancière, 2009:5). El sentido común recreado y repartido por el gobierno es dado a quienes pueden ser parte del relato nacional, es decir, funciona como un sistema de formas a priori que determinan lo visible y lo invisible de este proceso de reconstrucción social e histórica.

Un rastro controlado de visibilidad fue la presencia de quince mujeres vestidas de blanco y negro, familiares de detenidos desaparecidos, quienes bailaron la "Cueca sola", testimonio de dolor y esperanza, mientras que por los parlantes se emitía la siguiente frase: "Pero en esta fiesta de la democracia, no estamos todos, faltan muchos, los que aquí, en este estadio, sufrieron sin razón. La democracia de hoy nace también de los rostros ausentes para siempre"”. Una pequeña porción de nombres aparecía en el tablero del estadio mientras que cientos de personas levantaban sus pañuelos blancos, intentando desde las graderías acompañar el baile de estas mujeres. Este breve acto simbólico administra un modelo de interpretación de lo allí sucedido. Si bien, por un lado, se presenta como un gesto para la comprensión del dolor, por otro anuncia el agotamiento del conflicto, como si el acto de nombrar corrigiera la verdad y se cerrara la posibilidad de abrir un debate público sobre el genocidio cometido en la dictadura cívico-militar, sus causas y consecuencias.
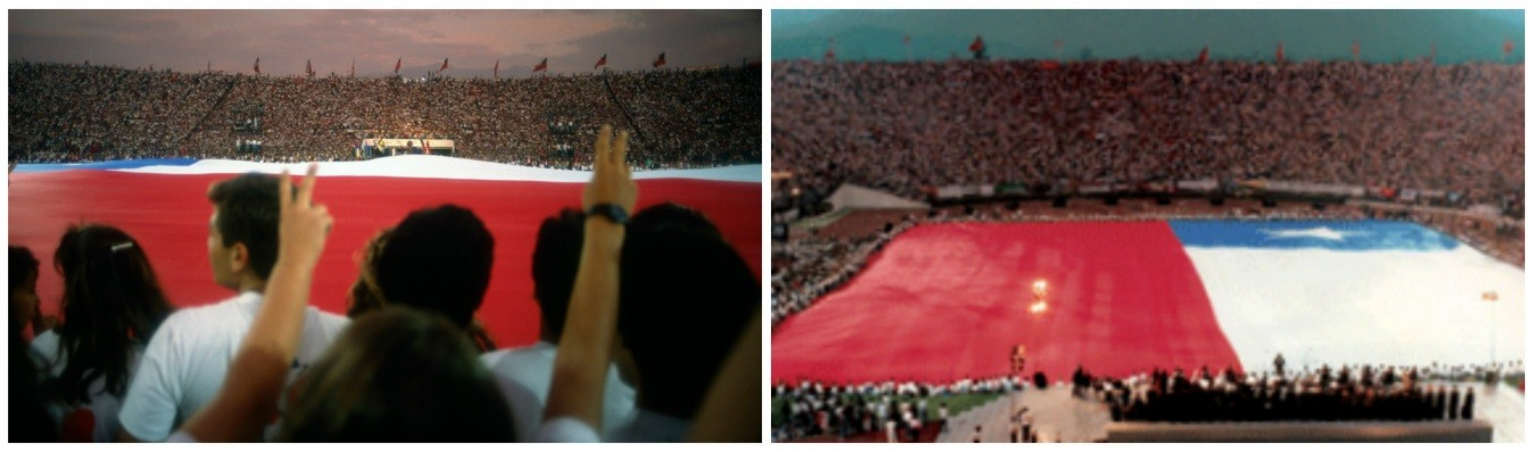

12 de marzo de 1990 - Archivo Memoria Chilena

3 Registro audiovisual. Yo amo los 90 Primer capítulo "Chile a las puertas del cambio". Producción de Canal 13. https://www.youtube.com/watch?v=hLqDzI0G5ag Revisada el 22 de mayo de 2015. 
Sin duda, el punto culmine de este "sicodrama colectivo" (Otano, 2006:131) fue el despliegue de una enorme bandera en manos de jóvenes, previo al discurso de Aylwin. La materialidad simbólica del ícono da pie a la reconstrucción del lazo y permite -momentáneamente- tocar el futuro de Chile con las manos. La necesidad por reparar o reinventar el pasado imprimen en la comunidad una imagen de esperanza, forjando una nueva representación de la identidad nacional. Sin embargo, el símbolo de la unión también es el símbolo del punto final puesto que su monumentalidad silencia todo tipo de diferencias y desacuerdos posibles. En ese sentido, las líneas de visibilidad del orden transicional, manifestadas en el uso de la bandera como veladura, forjan un sentimiento de arraigo, distanciándose de aquellos espacios conflictivos capaces de fisurar este nuevo libreto político e ideológico.

El orden para sentir o "las maneras de hacer que intervienen en las maneras de ser" (Rancière, 2009:11), quedan de manifiesto posteriormente en el discurso realizado por el Presidente electo: "Es hermosa y múltiple la tarea que tenemos por delante, en la convivencia entre los chilenos, cualesquiera que sean sus creencias, ideas, actividades o condición social. Sean civiles o militares" (Ortega y Moreno, 2002:227). En ese momento, las personas que poblaban las graderías del estadio se ven envueltas en un torbellino emotivo. La mención a los militares hizo estallar una estampida de silbidos en desaprobación de lo mencionado por Aylwin. El Presidente no da su brazo a torcer y prosigue enérgicamente, echando mano a su autoridad moral y reafirmando el objetivo de llevar a cabo su forma de reconciliación: "Sí señores, sí compatriotas, civiles o militares, Chile es uno solo" [...]. Las culpas de personas no pueden comprometer a todos, tenemos que ser capaces de reconstruir la unidad de la familia chilena [...]. Chile vuelve a la democracia y vuelve sin violencia, sin sangre, sin odio, vuelve por los caminos de la paz. En que no volvamos jamás a convertirnos unos chilenos en enemigos de otros chilenos" (ídem.). De un momento a otro, los espectadores de este primer llamado al orden de su representante comienzan a aplaudir vigorosamente sus palabras, desatando un ambiente de aprobación y conformidad con lo enunciado.

El sentido epopéyico de la restauración de la democracia vino acompañado de "líneas discontinuas, roturas y torceduras de una memoria no plena" (Richard, 2010:19), experiencias disgregadas y desarticuladas por el estado (Tapia, 2006:86), que posteriormente se abrirán paso, con más propiedad futuro en las manos- para detonar el bloque representacional de una historia homogénea y de sus protagonistas. Por entonces solo quedaba recuperar el país para que, como dice la canción del cierre del 
acto, Chile sea "nuevamente Chile". La última frase emitidas por el Presidente en su discurso fue: "Las futuras generaciones juzgarán nuestra conducta" (Ortega y Moreno, 2002:231). Y efectivamente eso fue así. La sentencia propuesta por el mismo gobierno fue un adelanto al cuestionamiento sobre el reparto de los afectos futuros, marcos de subjetivación política distanciados de la voz y del cuerpo de las nuevas generaciones que ponen en duda el proyecto democrático del país.

\section{Manos vacías y manos llenas: la comunidad de lo alcanzado}

Como hemos visto, la transición chilena se propuso neutralizar la fuerza social y política ligada críticamente al pasado dictatorial, desactivando sus recuerdos y visiones sobre la violencia llevada por los militares. El mecanismo para poner en marcha el modelo fue la imposición del consenso como forma de convivencia y el discurso de la unidad nacional. El peligroso dispositivo del consenso permitió alinear las conductas y los afectos de las personas "en torno a las disposiciones oficiales de moderación y resignación" (Richard, 2010:31). Esto trajo consigo la eliminación del uso público de algunas palabras, ejercicio nada nuevo pues la dictadura hizo lo suyo con algunas otras. La rabia e indignación fueron palabras -y emociones- que sonaban a muy bajo volumen a principios de los 90 . La mentada democracia, sostenida en una "ficción de una comunidad ideal" (Rancière, 2010:31), se habría encargado de sustituir el demos por una suerte de sujeto despojado del motor más sensible en la lucha por sus derechos políticos: sus afectos.

Si bien, los gobiernos posteriores perpetuaron esta forma de negociación, distanciando a la comunidad de sus maneras de reconocerse parte, con el tiempo la exclusión sistemática de otras formas de realidad posibilitó modos de resistencia frente a este orden afectivo y político. La diversidad de experiencias fueron el resultado de un posicionamiento desde el quiebre, y como tal, a partir del disenso. Un sujeto que ya no se define por su participación en la elección de sus representantes, dirá Rancière (2010), sino por su relación diferencial respecto al orden que se le asigna en una comunidad dada. Esto quiere decir, una plena conciencia del lugar que se tiene en la esfera pública. Sin embargo, es necesario no confundir recuperar con ocupar. El concepto de recuperación le otorga una significación política al espacio ganado -luchado-y jamás otorgado -cedido.

Con el paso de los años, el "monopolio político" (Tapia, 2006:88) representativo chileno comenzó a desmoronarse, evidenciando sus filiaciones con ciertos grupos de poder enriquecidos durante los 80 . 
$\overline{\text { Paulatinamente, se fue corriendo el velo que invisibilizaba la violencia estructural, la pervivencia de la }}$ institucionalidad gestada en dictadura y la gran desigualdad provocada por el modelo económico. Esta "vieja sociedad en decadencia" (Bloch, 1977: 3) fue mostrando sus fisuras a partir del desmantelamiento del fenómeno de la crisis: "del fenómeno soportado, pero no entendido; del fenómeno lamentado, pero no transformado" (Ibíd.). De acuerdo con esto, el horizonte de un presente posible y tangible se produce en la medida en que las personas -colectivos y organizaciones- comprenden que sus derechos políticos también corresponden a aquellas instancias de asociación y libre expresión, posibilitando "oportunidades formales de participación en la vida política" (Tapia, 2006:90). En ese sentido, entendemos el disenso como el arrebato del poder, como la desclasificación a través de la cual un grupo se desprende de la multiplicidad anónima marcando su inscripción en ese movimiento de partición-participación, como única posibilidad de existencia de la democracia.

En Chile, el primer punto de inflexión, que corre el velo de esta pretendida unidad, fue la captura de Pinochet en 1998. Por entonces, la prolongada presencia del ex-dictador -primero como Comandante en Jefe del Ejército y luego como Senador Vitalicio- caló hondo en la subjetividad de los chilenos. Su llegada al parlamento estuvo acompañada por diversas manifestaciones de quienes no estaban de acuerdo con que ocupara un escaño en el lugar más representativo del sistema democrático. Sin embargo, el quiebre final ocurre algunos meses después cuando Pinochet es arrestado en Londres. Las personas "sacudidas por el fanatismo o remecidos por la indignación" (Richard, 2010:55) ocuparon el espacio público e hicieron escuchar su voz desde distintos lugares del mundo. Este hecho revive inmediatamente el malestar que hacia fines de la década de los 90 parecía dormido. Los cuerpos desbordados salieron a las calles provocando el estallido de aquello latente durante años: el odio hacia el otro, distinto y rival. El consenso social, devenido en indiferencia, se quiebra en este nuevo escenario, provocando el desmantelamiento del guion democrático chileno.

Las manifestaciones patrióticas de fervor militarista se impusieron frente a quienes reclamaban justicia. Esto se ve reflejado en las acciones tomadas por el gobierno para traer a Pinochet al país, las cuales consiguen hacerlo luego de quinientos días de arresto y varias negociaciones diplomáticas que alegaban razones humanitarias para su extradición. La realización de un acto de bienvenida produjo enormes malestares debido a que terminó siendo un regreso triunfal. Pinochet de pie, camina por la losa del aeropuerto mientras que cientos de personas lo aplauden fervorosamente. La llegada, supuestamente 
sobria, del ex-dictador se convierte en un gran acto de provocación al país. Se trató de un regreso impune, entendido por fuera de todos los marcos de interpretación señalados anteriormente, relevando nuevamente los estrictos márgenes de la dictadura. Fue así como la historia pendiente colisionó contra quienes vendieron este modelo “amnésico y analgésico de transición” (Otano, 2006:465).

El entristecimiento irradiado desde el poder a través de la esperanza y la amenaza (Fundación Espai en Blanc, 2008), de alguna manera, debilita la voluntad de transformación. Sin embargo, solo la resistencia de los movimientos sociales puede lograr destituir paulatinamente este armazón político, convocando nuevas formas de sobrevivencia y lucha.
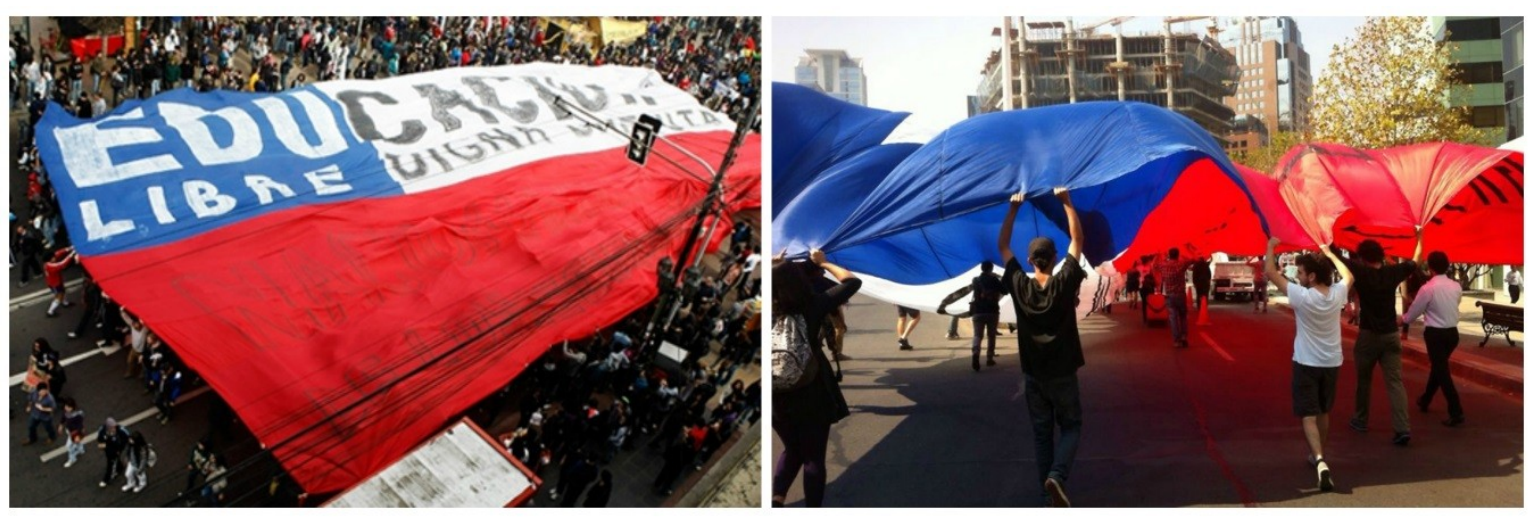

El movimiento estudiantil irrumpe en el escenario social y político con la fuerza de años de descontento y desigualdad, siendo uno de los más importantes desde el retorno a la democracia. La motivación de quienes participaban de este acontecimiento surge desde el profundo lugar del desacuerdo, desde el cambio en la percepción del modelo económico responsable de la privatización de la educación. La represión observada en las marchas despierta un sentimiento de impotencia y frustración que activa al movimiento social. Fue así como surgieron una serie de manifestaciones pacíficas y festivas que fueron incorporando otro sustrato a las marchas estudiantiles. La ocupación de los espacios físicos tuvo un giro hacia una ocupación simbólica con alto contenido político. Un ejemplo de esto fue la recuperación de la bandera para resignificarla desde su ocupación en las calles, instalando la consigna "Educación Pública, Gratuita y de Calidad" como marco para diversas manifestaciones sociales. La presencia visual -y material- del símbolo inevitablemente nos recuerda aquella primera bandera de regreso a la democracia que representaba el fin de un modelo opresor, sin embargo, la bandera de los estudiantes nos interroga 
sobre las herencias de la dictadura, las que fueron administradas por los siguientes gobiernos democráticos.

En ese sentido, el símbolo cuestiona y relativiza la perspectiva totalizante de la identidad mediada por una repartición de los afectos, cuestionando la norma y desarmando la sutura convenida años antes. La insubordinación - de las personas y los símbolos- presume un tipo de desobediencia que denuncia la violencia estructural del Estado, quebrando su totalidad. Resulta interesante la idea de subsuelo político, presentada por Tapia, como aquel conjunto de prácticas y discursos políticos capaz de contener "crítica, desdén, ironía, sabotaje, parodia, [...] formas de solidaridad y comunicación" (Tapia, 2006:97). La posición del subsuelo es siempre actual, pues "se trata de un regreso al presente para redescribir nuestra contemporaneidad; reinscribir nuestra comunidad humana e histórica; tocar el futuro por el lado de acá" (Bhabha, 2002: 23). El poder creador de la desobediencia logra politizar cada esfera de la vida cotidiana, afirmando un tipo de convivencia consciente de su rol como agente de cambio. En ese sentido, tomar el futuro en las manos significa posicionarse desde el presente conflictivo y en crisis, con el fin de palparlo y hacerlo propio, para liberarse de la "esquizofrenia de lo democrático" y abrir un horizonte de derechos y prácticas legítimas de participación.

\section{Conclusión}

La pregunta realizada por Lechner hace algunos años ¿No podría ser el desencanto (en este sentido) una situación fértil para la democracia? (Lechner, 1988:18) resulta relevante y significativa. Ante esto el autor señala que "a menudo se analizan la dinámica institucional, la estrategia de los actores y los condicionamientos económicos sin considerar debidamente la experiencia diaria de la gente, sus miedos y sus deseos (Lechner,1988:9). El desencanto posicionado en la cotidianidad cuestiona la repartición de los afectos como orden para pertenecer, mostrando un anverso y un reverso. Por un lado, se presenta como medio de control afectivo, pero por otro, abre la posibilidad a otros mundos y marcos para la acción, formando un contrapoder capaz de resistir a la propuesta política estatal. Siguiendo con esto último, resulta necesario tener nociones sobre lo que se lucha, lejos de las convenciones sobre victoria y derrota. El espacio abierto al disentimiento, innegable desde el 2011 en adelante, propone otras estrategias ante la facticidad que se nos impone y, de cierta manera, establece una lucha por lo político. 
El Colectivo Situaciones -en su texto "Politizar la tristeza" (Fundación Espai en Blanc, 2008:306)delimita claramente márgenes para una nueva interpretación de lo social, constituyendo un horizonte de búsqueda en el presente: se propone i) conquistar una mayor soberanía para la vida diaria, ii) comprender la memoria política como medio para desarticular las fórmulas del pasado y recuperar nuestras posibilidades, iii) entender los procesos más allá de la derrota, estableciendo un tiempo continuo y permanente de lucha, iv) no renunciar a darse tiempos, palabras y formas propias para evitar ser conquistados, v) elaborar un espacio público no estatal para no quedar atrapados en los procedimientos de normalización y, finalmente, vi) repensar lo colectivo como un lugar situado en el mundo, como formas vivas de elaboración. De esta manera, el pensamiento político tiene como fundamento hacer visible lo colectivo, relacionando y reconstruyendo contextos con el fin de compartir -más que repartir- sentidos y sentires en la construcción del presente, y así, conseguir una transformación de nuestras formas simbólicas y afectivas de convivencia y lucha.

\section{Referencias bibliográficas}

Bhabha Homi (2002), El lugar de la cultura, Buenos Aires, Manantial.

Bloc, Ernest (1977), El principio de esperanza. Tomo I, Madrid, Biblioteca Filosófica Aguilar.

Délano Manuel (1989), “iLes ganamos con un lápiz!” Diario El País. 16 de diciembre de 1989. Web Disponible en: http://elpais.com/diario/1989/12/16/internacional/629766006_850215.html (Revisado el 7 de abril de 2018)

Fundación Espai en Blanc (coord.) (2008), Luchas autónomas en los años setenta, Madrid, Traficantes de sueños.

Lechner Norbert (1988), Los patios interiores de la democracia. Subjetividad y política, Santiago de Chile, FLACSO.

Nancy Jean-Luc (2013), Archivida. Del sintiente y del sentido, Buenos Aires, Quadrata.

Rancière Jacques (2010), En los bordes de lo político, Buenos Aires, La Cebra. 
(2009), El reparto de lo sensible. Estética y política. Santiago de Chile, LOM.

Otano Rafael (2006), Nuevo crónica de la transición, Santiago de Chile, LOM.

Tapia Luis (2006), Política salvaje, La Paz, Muela del Diablo Editores.

Richard, Nelly (2010), Crítica a la memoria (1990-2010), Santiago de Chile, Ediciones Universidad Diego Portales.

Eugenio Ortega R., Carolina Moreno B. (compiladores) (2002), ¿La Concertación desconcertada?: Reflexiones sobre su historia y su futuro, Santiago de Chile, LOM.

Yo amo los 90 Primer capitulo "Chile a las puertas del cambio", Producción de Canal 13. Web. Disponible en: http://www.13.cl/programa/yo-amo-los-90/videos/chile-a-las-puertas-del-cambio (Revisada el 22 de mayo de 2015) 